Acknowledgement: Study funded by GSK. Gosia Carless, PhD, Fishawack Indicia Ltd, UK, provided editorial assistance funded by GSK. Disclosure of Interests: Christopher Collins Grant/research support from: Exagen, Consultant for: Exagen, AbbVie, Speakers bureau: Exagen, AbbVie, Novartis, Josefina Cortés-Hernández Grant/research support from: GSK, Speakers bureau: GSK, Mercedes García Grant/research support from: GSK, Speakers bureau: GSK, Johannes von Kempis: None declared, Andreas Schwarting Grant/research support from: GSK, Pfizer, AbbVie, Novartis, Roche, Speakers bureau: GSK, Novartis, Zahi Touma Grant/research support from: GSK Canada, Consultant for: UBC, Pfizer, Janssen, Inc, Shannon Ferrante Shareholder of: GSK, Employee of: GSK, Milena Kurtinecz Shareholder of: GSK, Employee of: GSK, Kerry Gairy Shareholder of: GSK, Employee of: GSK DOI: 10.1136/annrheumdis-2019-eular.7637

\section{FRI0190 INCIDENCE OF ANTIMALARIALS-INDUCED RETINOPATHY IN INFLAMMATORY RHEUMATIC DISEASES, USING OCT AND VISUAL FIELD TEST : A SYSTEMATIC REVIEW AND META-ANALYSIS}

CAGNY Hélène DE ${ }^{1}$, Jacques Morel ${ }^{1,2}$, Bernard Combe ${ }^{1,2}$, Cecile GaujouxViala $^{3,4}$, Cédric Lukas ${ }^{1,2}$. ${ }^{1}$ University of Montpellier, Montpellier, France; ${ }^{2}$ University hospital, Rheumatology, Montpellier, France; ${ }^{3}$ University of Nîmes, Nîmes, France; ${ }^{4}$ University hospital, Rheumatology, Nîmes, France

Background: Antimalarials (AM) are frequently used as first-line therapy in mild inflammatory diseases, because of a good benefit/risk ratio. Recently, their benefit on long term cardiovascular risk in RA patients has been demonstrated [1, 2]. Their most severe side effect is retinopathy, which can potentially lead to blindness, but remains reversible if detected early, provided the treatment is stopped. This complication has been described early [3], but its incidence remains uncertain. A recent update of the American Association of Ophtalmology (AAO) recommendations on screening for chloroquine and hydroxychloroquine retinopathy, suggests to screen patients under $\mathrm{AM}$ treatment, with a frequency depending on risk factors, and with the systematic and minimal use of Optical Coherence Tomography (OCT) and Visual Field (VF) test, completed by others tests if required [4].

Objectives: We aimed at estimating the exact incidence of AM-induced retinopathy, based on available published literature about this issue, with particular reference to detection performed with OCT and VF test.

Methods: A systematic literature search was conducted in Pubmed, Cochrane and Embase databases until April 6th 2018, completed by a manual search in references from the resulting selected articles. We first selected all publications about the incidence of AM-associated retinopathy in patients treated for inflammatory diseases and included them in the systematic literature search. Among them, and in order to minimize heterogeneity of results, we focused on those which had used at least OCT and VF test, as recommended by the AAO, to perform a meta-analysis. Analysis was conducted using MetaXL for Microsoft Excel, applying the Inverse of Variance method.

Results: Among the 3890 articles of potential interest, we selected 91 articles appropriately addressing the topic and included them in the systematic literature search. They were published between 1964 and 2018, with variable population sizes (10 to 3580 patients). Patients were treated with hydroxychloroquine, chloroquine or both for an inflammatory disease (usually lupus or rheumatoid arthritis). Mean treatment duration ranged from 1 to 14,1 years. Most of them were retrospectively designed, and diagnostic methods were diverse. For the aforementioned meta-analysis, we used data from 16 articles published between 2010 and 2018, in which every patient had at least OCT and VF Test. We found a pooled estimate of incidence of $6.05 \%$ (IC 95\% [5.18 - 7.31]), with a 12 heterogeneity coefficient of $80 \%$.

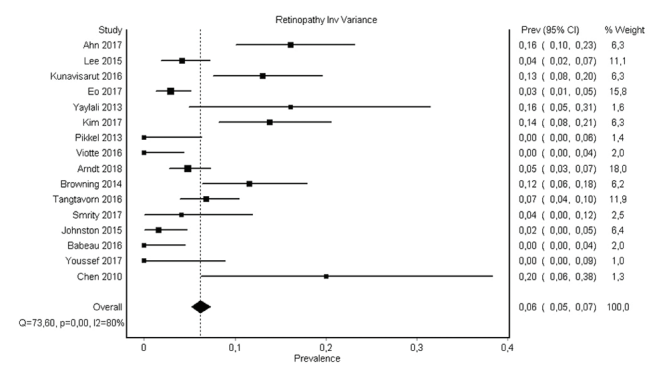

Conclusion: We found a pooled incidence of approximately $6 \%$ of AMinduced retinopathy when OCT and VF test are used. However diagnostic criteria are not consensually well-defined, leading to heterogeneous data.

\section{REFERENCES}

[1] Rempenault C, Combe B, Barnetche T, et al. Metabolic and cardiovascular benefits of hydroxychloroquine in patients with rheumatoid arthritis: a systematic review and meta-analysis. Ann Rheum Dis2017.

[2] Mathieu S, Pereira B, Tournadre A, et al. Cardiovascular effects of hydroxychloroquine: a systematic review and meta-analysis. Ann Rheum Dis2017.

[3] Hobbs H, Sorsby A, Freedman A: Retinopathy following chloroquine ther apy. Lancet 1959; II: 478.

[4] Marmor MF, Kellner U, Lai TY, et al, American Academy of Ophthalmology Statement. Recommendations on screening for chloroquine and hydroxychloroquine retinopathy (2016 revision).Ophthalmology. 2016;123:13861394.

Disclosure of Interests: Hélène DE CAGNY: None declared, Jacques Morel: None declared, Bernard Combe Consultant for: Abbvie, BristolMyers Squibb, Gilead, Janssen, Eli Lilly, MSD, Novartis, Pfizer, RocheChugai, Sanofi, UCB, Cecile Gaujoux-Viala Consultant for: Speaking and/ or consulting fees from AbbVie, Amgen, Bristol-Myers Squibb, Celgene, Eli Lilly, Gilead, Janssen, Merck-Serono, Medac, Nordic Pharma, Novartis, Pfizer, Roche, Sandoz, Sanofi and UCB Pharma., Speakers bureau: Speaking and/or consulting fees from AbbVie, Amgen, Bristol-Myers Squibb, Celgene, Eli Lilly, Gilead, Janssen, Merck-Serono, Medac, Nordic Pharma, Novartis, Pfizer, Roche, Sandoz, Sanofi and UCB Pharma. Cédric Lukas: None declared

DOI: 10.1136/annrheumdis-2019-eular.5146

\section{FRI0191 TREATMENT OF REFRACTORY POOR APL-RELATED OBSTETRIC OUTCOMES WITH TNF-ALPHA BLOCKERS: MATERNAL-FETAL OUTCOMES IN A SERIES OF 18 CASES}

Jaume Alijotas-Reig ${ }^{1}$, Enrique Esteve-Valverde ${ }^{2}$, Elisa Llurba ${ }^{3}$, Josep Mํㅡ. Gris ${ }^{4}$. ${ }^{1}$ Systemic Autoimmune Diseases Unit. Department of Internal Medicine-1. Vall d'Hebron University Hospital. Barcelona. Professor of Medicine. Department of Medicine. Faculty of Medicine. Universitat Autònoma de Barcelona., Barcelona, Spain; ${ }^{2}$ Staff. Department of Internal Medicine. Althaia Network Health. Manresa, Barcelona, Spain; ${ }^{3}$. Head. Obstetric and Ginecology Department. Sant Pau University Hospital. Universitat Autònoma de Barcelona., Barcelona, Spain; ${ }^{4}$ Staff. Reproductive Medicine Unit. Obstetric Department. Vall d'Hebron University Hospital. Barcelona. Universitat Autònoma de Barcelona, Barcelona, Spain

Background: No absolute data on the treatment of antiphospholipid antibodies (aPL) related to refractory obstetric complications exist to date. TNF- $\alpha$ play a major role in this disorder.

Objectives: To assess the effectiveness of TNF- $\alpha$ blockers in 18 aPLpositive women with recurrent infertility after therapy with low-molecularweight heparin (LMWH) plus aspirin (LDA) plus hydroxychloroquine (HCQ).

Methods: Prospective case-series of 12 women fulfilling Sydney criteria for obstetric antiphospholipid syndrome (OAPS) and 6 with incomplete forms (OMAPS). All women tested positive for aPL at least twice. Noncriteria aPL were tested in 15/18. Complement, TNF- $\alpha$ and IL-10 were also evaluated. Women were closely monitored for fetal well-being and possible malformations throughout gestation and the postpartum period.

Results: Sixteen patients were started on adalimumab and 2 on certolizumab. Twelve women completed gestation: 9 at term and 3 pre-term. Differences in laboratory categories and outcomes were observed when OAPS and OMAPS were compared. First trimester miscarriage or implantation failure recurred in 6 cases, all of the OAPS group. Malformations were not seen in the newborns.

Conclusion: Overall, good obstetric results were obtained in $70 \%$ of previous $\mathrm{LMWH}-\mathrm{LDA}+\mathrm{HCQ}$ refractory cases. TNF- $\alpha$ blockers were well tolerated without adverse effects. The combination of LMWH plus LDA plus TNF- $\alpha$ blockers appears to be a promising treatment for refractory obstetric complaints related to aPL; nevertheless, outcome differences between OAPS and OMAPS do exist. 


\section{REFERENCES:}

[1] Yamaguchi Y, Noriyuki N, Kaburaki J, Kobayashi K, Matsuura E, Kuwana M. Excessive exposure to anionic surfaces maintains autoantibody response to B2-glycoprotein I in patients with antiphospholipid syndrome. Blood 2007;110:4312-18.

[2] Miyakis S, Lockshin MD, Atsumi T, Branch DW, Brey RL, Cervera R, Derksen RH, DE Groot PG, Koike T, Meroni PL, Reber G, Shoenfeld Y, Tincani A, Vlachoyiannopoulos PG, Krilis SA. International consensus statement on an update of the classification criteria for definite antiphospholipid syndrome. J Thromb Haemost 2006; 4:295-306.

[3] Alijotas-Reig J, Vilardell-Tarrés M. Is obstetric antiphospholipid syndrome a primary nonthrombotic, proinflammatory, complement-mediated disorder related to antiphospholipid antibodies? Obstet Gynecol Surv 2010: 65:3945.

[4] Berman J, Girardi G, Salmon JE. TNF-alpha is a critical effector and a target for therapy in antiphospholipid antibody-induced pregnancy loss. J Immunol 2005;174:1222-1226.

[5] Meroni PL, Borghi MO, Raschi E,Tedesco F. Pathogenesis of antiphospholipid syndrome: understanding the antibodies. Nat Rev Rheumatol 2011;7:330-39.

[6] Brogin Moreli J, Cirino Ruocco AM, Vernini JM, Rudge MV, Calderon IM. Interleukin 10 and tumor necrosis factor-alpha in pregnancy: aspects of interest in clinical obstetrics. ISRN Obstet Gynecol. 2012;2012:230742.

Disclosure of Interests: None declared

DOI: 10.1136/annrheumdis-2019-eular.1279

\section{FRI0192 A SYSTEMATIC LITERATURE REVIEW TO INFORM THE 2019 UPDATE OF THE EULAR RECOMMENDATIONS FOR THE TREATMENT OF SYSTEMIC LUPUS ERYTHEMATOSUS}

Antonis Fanouriakis ${ }^{1}$, Myrto Kostopoulou ${ }^{2}$, Alessia Alunno ${ }^{3}$, Martin Aringer ${ }^{4}$, Ingeborg Bajema ${ }^{5}$, John N. Boletis ${ }^{6}$, Ricard Cervera ${ }^{7}$, Andrea Doria ${ }^{8}$, Caroline Gordon ${ }^{9}$, Marcello Govoni ${ }^{10}$, Frederic Houssiau ${ }^{11}$, David Jayne ${ }^{12}$, Marios Kouloumas ${ }^{13}$, Annegret Kuhn ${ }^{14}$, Janni Lisander Larsen ${ }^{15}$,

Kirsten Lerstrom ${ }^{16}$, Gabriela Moroni ${ }^{17}$, Marta Mosca ${ }^{18}$, Matthias Schneider ${ }^{19}$, Josef S. Smolen ${ }^{20}$, Elisabet Svenungsson ${ }^{21}$, Vladimir Tesar ${ }^{22}$, Angela Tincani ${ }^{23}$, Anne Troldborg ${ }^{24}$, Ronald van Vollenhoven ${ }^{25}$, Jörg Wenze $\left.\right|^{26}$, George Bertsias ${ }^{27}$,

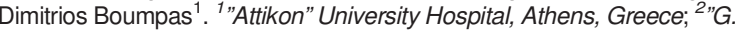
Gennimatas" General Hospital, Athens, Greece; ${ }^{3}$ University of Perugia, Perugia, Italy; ${ }^{4}$ University Medical Center and Faculty of Medicine Carl Gustav Carus at the TU Dresden, Dresden, Germany, ${ }^{5}$ Leiden University Medical Center, Leiden, Netherlands; " "Laikon" Hospital, National and Kapodistrian University of Athens, Medical School, Athens, Greece; ${ }^{7}$ Hospital Clinic, Barcelona, Spain; ${ }^{8}$ University of Padova, Padova, Italy, ${ }^{9}$ Institute of Inflammation and Ageing, University of Birmingham, Birmingham, United Kingdom; ${ }^{10}$ University of Ferrara, Azienda Ospedaliero-Universitaria Sant'Anna Ferrara, Ferrara, Italy, ${ }^{11}$ Université catholique de Louvain, Brussels, Belgium; ${ }^{12}$ University of Cambridge, Cambridge, United Kingdom; ${ }^{13}$ Cyprus League Against Rheumatism, Aglantzia, Cyprus; ${ }^{14}$ University Hospital Muenster, Muenster, Germany, ${ }^{15}$ Rheumatology and Spine Diseases Centre, Rigshospitalet, Copenhagen, Denmark, ${ }^{16}$ Lupus Europe, Farum, Denmark; ${ }^{17}$ Fondazione IRCCS Ca' Granda Ospedale Maggiore Policlinico, Milan, Italy; ${ }^{18}$ University of Pisa, Pisa, Italy, ${ }^{19}$ UKD, Heinrich-Heine University, Düsseldorf, Düsseldorf, Germany; ${ }^{20}$ Medial University of Vienna, Vienna, Austria; ${ }^{21}$ Karolinska Institutet and Karolinska University Hospital, Stockholm, Sweden; ${ }^{22} 1$ st Faculty of Medicine and General University Hospital, Charles University, Prague, Czech Republic; ${ }^{23}$ University of Brescia, Brescia, Italy, ${ }^{24}$ Aarhus University Hospital, Aarhus, Denmark, ${ }^{25}$ Amsterdam University Medical Centers, Amsterdam, Netherlands; ${ }^{26}$ University Hospital Bonn, Bonn, Germany; ${ }^{27}$ University Hospital of Heraklion, Heraklion, Greece

Background: Culminating evidence over the past decade regarding management of systemic lupus erythematosus (SLE) called for an update of the 2008 EULAR recommendations for the treatment of the disease.

Objectives: Systematic review of the literature (SLR) to inform the 2019 EULAR recommendations for the management of SLE.

Methods: SLR of Pubmed from 01/2007 to 12/2017 for questions (selected through Delphi excercise) regarding: i) efficacy/safety of different drugs used in SLE, ii) treatment of specific manifestations, iii) monitoring and treatment goals and iv) comorbidities and adjunct therapy. Evidence was categorised based on design and validity of available studies [Oxford Centre for Evidence-Based Medicine 2011 Levels of Evidence (LOE)] and strength of statements was graded [Grading of recommendation (GoR), assessment, development and evaluations, GRADE]].

Results: Main topics supported by strong evidence base included: Association of hydroxychloroquine (HCQ) use with favourable outcomes (LoE 1b,
GoR A), belimumab for extrarenal disease (LoE 1a, GoR A), efficacy of antimalarials in skin disease (LoE 1a, GoR A), mycophenolate mofetil (MMF) for induction and maintenance therapy of lupus nephritis (LN) and cyclophosphamide (CYC) in severe LN (LoE 1b, GoR A). Weak evidence supported the value of repeat kidney biopsy in refractory LN (LoE 4, GoR C), all second-line agents for skin disease (LoE 4, GoR C) and efficacy of most first and second-line treatments for thrombocytopenia (LoE 4, GoR C). Moderate LoE was found for all other questions (Table).

Conclusion: A SLR for the treatment of SLE found the highest LoE for benefits of $\mathrm{HCQ}$, efficacy of belimumab for extrarenal disease and MMF and IV-CYC in LN.

\section{Acknowledgement: European League Against Rheumatism}

Disclosure of Interests: Antonis Fanouriakis Paid instructor for: Amgen, GSK, Speakers bureau: Abbvie, Enorasis, Genesis Pharma, Myrto Kostopoulou: None declared, Alessia Alunno: None declared, Martin Aringe Grant/research support from: Roche, Consultant for: AstraZeneca and Eli Lilly, Ingeborg Bajema Consultant for: GSK, John N. Boletis: None declared, Ricard Cervera: None declared, Andrea Doria: None declared, Caroline Gordon Grant/research support from: Sandwell and West Birming ham Hospitals NHS Trust have received funding from UCB to support research work done by my research group that was unrelated to any pharmaceutical product or clinical trial., Consultant for: I have provided consultancy advice and taken part in scientific advisory boards on the design and analysis of clinical trials and the management of lupus for GSK, EMD Serono and UCB. I have taken part in adjudication and safety monitoring committees for BMS., Speakers bureau: I have been paid by UCB for speaking at meetings., Marcello Govoni Paid instructor for: Pfizer, Roche, Speakers bureau: Pfizer, Abbvie, MSD, Roche, Eli-Lilly, Celgene, Sanofi, Janssen, Frederic Houssiau: None declared, David Jayne Grant/research support from: David Jayne has received research grants from Chemocentryx, GSK, Roche/Genentech and Sanofi-Genzyme. He has received consultancy fees from Astra-Zeneca, Boehringer-Ingelheim, Chemocentryx, Chugai, GSK, Infla-RX, Insmed and Takeda, Marios Kouloumas: None declared, Annegret Kuhn Grant/research support from: Biogen, Galderma, GlaxoSmithKline, LeoPharma, Speakers bureau: La Roche Posay, Janni Lisander Larsen: None declared, Kirsten Lerstrom: None declared, Gabriela Moroni: None declared, Marta Mosca Paid instructor for: GlaxoSmithKline, Lilly, UCB, Matthias Schneider Grant/research support from: GlaxoSmithKline and UCB Pharma for performing the LuLa-study., Speakers bureau: Chugai, Josef S. Smolen Grant/research support from: AbbVie, Eli Lilly, Janssen, MSD, Pfizer Inc, Roche, Consultant for: AbbVie, Amgen, AstraZeneca, Astro, Celgene, Celtrion, Eli Lilly, GlaxoSmithKline, ILTOO, Janssen, Medimmune, MSD, Novartis-Sandoz, Pfizer Inc, Roche, Samsung, Sanofi, UCB, Speakers bureau: AbbVie, Amgen, AstraZeneca, Astro, Celgene, Celtrion, Eli Lilly, GlaxoSmithKline, ILTOO, Janssen, Medimmune, MSD, Novartis-Sandoz, Pfizer Inc, Roche, Samsung, Sanofi, UCB, Elisabet Svenungsson: None declared, Vladimir Tesar: None declared, Angela Tincani Consultant for: UCB, Pfizer, Abbvie, BMS, Sanofi, Roche, GSK, AlphaSigma, Lilly, Jannsen, Cellgene, Novartis, Anne Troldborg: None declared, Ronald van Vollenhoven Grant/research support from: AbbVie, Amgen, Bristol-Myers Squibb, GlaxoSmithKline, Pfizer, Roche, and UCB, Consultant for: AbbVie, AstraZeneca, Biotest, Bristol-Myers Squibb, Celgene, Crescendo, GlaxoSmithKline, Janssen, Lilly, Merck, Novartis, Pfizer, Roche, UCB, and Vertex. Speakers bureau: AbbVie, AstraZeneca, Biotest, Bristol-Myers Squibb, Celgene, Crescendo, GlaxoSmithKline, Janssen, Lilly, Merck, Novartis, Pfizer Roche, UCB, and Vertex., Jörg Wenzel Grant/research support from: GSK, Incyte, Consultant for: Biogen, Leo, Paid instructor for: Novartis, George Bertsias: None declared, Dimitrios Boumpas: None declared DOI: 10.1136/annrheumdis-2019-eular.6348 